\title{
As orações concessivas introduzidas por aunque nas modalidades falada e escrita do espanhol peninsular
}

DOI: http://dx.doi.org/10.21165/el.v49i3.2626

\author{
Sandra Denise Gasparini-Bastos ${ }^{1}$ \\ Beatriz Goaveia Garcia Parra-Araujo ${ }^{2}$
}

\section{Resumo}

O presente trabalho analisa as orações concessivas introduzidas pelo juntor espanhol aunque provenientes tanto de dados de modalidade falada como de modalidade escrita do espanhol peninsular, a fim de verificar se as propriedades pragmáticas e semânticas dessas orações são motivadas pelo modo de produção dos enunciados concessivos - oral ou escrito. Para tanto, adotamos como aparato teórico a Gramática DiscursivoFuncional (HENGEVELD; MACKENZIE, 2008), modelo funcionalista de análise que se organiza em quatro níveis hierarquicamente dispostos: Interpessoal (pragmático), Representacional (semântico), Morfossintático e Fonológico. O córpus adotado para esta pesquisa é composto por entrevistas orais, extraídas do Projeto PRESEEA, e por editoriais jornalísticos publicados on-line pelo jornal espanhol El País. A análise foi realizada com base em dois fatores: a camada de atuação da oração concessiva introduzida por aunque e a informatividade do conteúdo transmitido por essas orações.

Palavras-chave: aunque; modalidade falada; modalidade escrita; espanhol peninsular; informatividade.

\footnotetext{
1 Universidade Estadual Paulista "Júlio de Mesquita Filho" (UNESP), São José do Rio Preto, São Paulo, Brasil; sandra.gasparini@unesp.br; https://orcid.org/0000-0001-5968-8450

2 Universidade Estadual Paulista "Júlio de Mesquita Filho" (UNESP), São José do Rio Preto, São Paulo, Brasil; biagarcia.parra@hotmail.com; https://orcid.org/0000-0002-4640-9325
} 


\title{
The concessive clauses introduced by aunque in spoken and written mode of Iberian Spanish
}

\begin{abstract}
This work analyzes the concessive clauses introduced by the conjunction aunque from both spoken and written data of Iberian Spanish in order to verify if the pragmatic and semantic properties of these clauses are motivated by the mode of production of the concessive utterances - oral or written. To this end, we follow the Functional Discourse Grammar framework (HENGEVELD; MACKENZIE, 2008), which provides four hierarchically organized levels of analysis: Interpersonal (pragmatics), Representational (semantics), Morphosyntactic and Phonological levels. The corpus selected for this research consists of spoken interviews from the PRESEEA Project and journalistic editorials published online by the Spanish newspaper El País. Data analysis was guided by two factors: the layer of the concessive clauses introduced by aunque and the informativeness of the evoked content by these clauses.
\end{abstract}

Keywords: aunque; spoken language; written language; Iberian Spanish; informativeness.

\section{Introdução}

Conforme Alarcos Llorach (1999), as orações concessivas podem ser definidas, de uma maneira geral, como aquelas que apresentam um obstáculo ou dificuldade em relação ao que é dito na oração principal, sem que esse obstáculo impeça seu cumprimento. Em língua espanhola, a concessão pode ser expressa por diferentes juntores: aunque, aun, aun cuando, a pesar de (que), por muy/mucho que, por más que, si bien, y eso que. Dentre as conjunções concessivas empregadas no espanhol, nossa análise volta-se para a conjunção aunque, a mais usual, conforme afirmam a Real Academia Española (2009), de uma perspectiva normativa, e Crevels (1998), de uma perspectiva descritiva funcionalista.

A partir de amostras do espanhol peninsular falado e escrito, Parra (2016) estudou as orações concessivas introduzidas por aunque, tendo como aparato teórico o modelo da Gramática Discursivo-Funcional (GDF), proposto por Hengeveld e Mackenzie (2008), o qual prevê a existência de 4 níveis de análise: o Nível Interpessoal (pragmático), o Nível Representacional (semântico), o Nível Morfossintático e o Nível Fonológico³. Em sua análise, a autora verificou que a conjunção aunque introduz, com maior frequência, Conteúdos Proposicionais, unidades que pertencem ao Nível Representacional, mas também pode introduzir unidades do Nível Interpessoal, mostrando a alta produtividade desta conjunção no espanhol falado e escrito.

3 O emprego de maiúsculas para determinados termos da Gramática Discursivo-Funcional bem como para algumas variáveis obedece a uma normatização imposta pelo próprio modelo teórico. 
O presente trabalho parte da análise realizada por Parra (2016) para verificar, a partir dos subtipos oracionais introduzidos por aunque, quais são os usos mais prototípicos das modalidades falada e escrita no idioma espanhol. Como critérios de análise, observamos (i) a camada de atuação da oração concessiva a partir da estrutura proposta pela GDF; e (ii) a informatividade do conteúdo transmitido por essas orações, isto é, se a informação expressa é pressuposta ou não-pressuposta pelos interlocutores. Para tanto, empregamos o mesmo córpus organizado pela autora, composto por entrevistas orais semidirigidas (para a análise da modalidade falada) e por editoriais jornalísticos (para a análise da modalidade escrita).

Os dados de língua falada consistem em 74 entrevistas do espanhol peninsular pertencentes ao Projeto PRESEEA (Proyecto para el Estudio Sociolingüístico del Español de España y de América) ${ }^{4}$, coordenado pelo professor Francisco Moreno Fernández, da Universidade de Alcalá de Henares (Espanha). Embora o projeto contemple diversas cidades espanholas e hispano-americanas, os dados analisados no presente estudo limitam-se às cidades espanholas de Alcalá de Henares (17 entrevistas), Madri (12 entrevistas), Valência (27 entrevistas) e Granada (18 entrevistas), cujos dados já estão transcritos e disponíveis para consulta.

Os dados de língua escrita estão representados pelo gênero editorial jornalístico e a amostra está composta por 667 textos, publicados on-line pelo jornal El País, em sua versão espanhola, no período de 02 de janeiro de 2013 a 27 de novembro de $2013^{5}$. A temática dos textos trata, principalmente, de economia e política da Espanha, da Europa e do mundo.

Os editoriais enquadram-se no gênero textual argumentativo, pois discutem assuntos de interesse público em consonância com as ideologias do veículo de informação em que se inserem (jornal, revista ou outro meio), de modo que os assuntos abordados procuram convencer o leitor a concordar com o ponto de vista apresentado pela equipe editorial. Conforme aponta Chaves (2014), os conectivos são elementos importantes na construção da argumentação no gênero editorial, já que refletem estratégias argumentativas do autor e colaboram para convencer o leitor a fazer uma determinada interpretação do texto. Assim, os editoriais jornalísticos representam uma fonte produtiva para orações concessivas, nosso objeto de análise, e podem revelar empregos de determinada conjunção, como aunque, por exemplo, que mostram valores diferentes de uma típica conjunção subordinante.

4 Disponível em http://preseea.linguas.net/

5 Córpus organizado por Parra (2016). 
Como forma de garantir que os dois conjuntos de dados fossem comparáveis, os textos orais e os textos escritos foram homogeneizados quanto ao número de palavras, o que resultou numa amostra de 304.763 palavras no conjunto de textos orais e numa amostra de 304.764 palavras no conjunto de textos escritos.

Para alcançar o objetivo proposto - verificar se os tipos oracionais introduzidos por aunque são específicos da modalidade falada ou escrita -, este trabalho se organiza da seguinte forma: na seção inicial, caracterizamos as modalidades falada e escrita da língua, a partir da proposta de Marcuschi (2001); na sequência, apresentamos sucintamente o modelo teórico da Gramática Discursivo-Funcional, que embasa nossa classificação para os subtipos oracionais introduzidos por aunque, bem como a classificação proposta por Parra (2016), que tomamos como ponto de partida; finalmente, apresentamos os resultados da análise das ocorrências identificadas nas modalidades falada e escrita, com base nos dois critérios estabelecidos: camada de atuação da oração introduzida por aunque, conforme a Gramática Discursivo-Funcional, e a informatividade do conteúdo dessas orações. Por fım, apresentamos as considerações finais resultantes da análise.

\section{As modalidades falada e escrita da língua}

Tendo em vista que, neste trabalho, analisamos as orações concessivas iniciadas por aunque presentes tanto em textos falados como em textos escritos do espanhol peninsular, julgamos necessário explicitar as noções de fala e de escrita que norteiam esta pesquisa. Em uma análise de natureza funcionalista como a que aqui se propõe, as semelhanças e as diferenças entre fala e escrita não podem ser investigadas sem se levar em conta a produção dos textos nessas modalidades em contextos reais de comunicação ou, nas palavras de Marcuschi (2001), sem considerar que a modalidade falada e a modalidade escrita abrigam conjuntos de práticas sociais.

Ao selecionar amostras de ambas as modalidades, estamos em consonância com Marcuschi (2001, p. 37), que, inspirado no trabalho de Koch e Österreicher (1990), considera que "as diferenças entre fala e escrita se dão dentro do contínuo tipológico das práticas sociais de produção textual e não na relação dicotômica de dois polos opostos". Para Marcuschi (2001), as modalidades falada e escrita são realizações de uma gramática única, porém com características peculiares, como o meio de produção (sonoro ou gráfico) e a concepção discursiva (oral ou escrita). Seguindo, então, essas especificações, a fala é considerada como sendo de concepção oral e de meio sonoro, enquanto a escrita é de concepção escrita e de meio gráfico.

As particularidades apresentadas pelas modalidades falada e escrita, como os recursos prosódicos ou os recursos gráficos, respectivamente, evidenciam que ambas são práticas multissistêmicas, que podem se valer de outros recursos para além da oralidade e da grafia. 
As diferenças comumente apontadas entre fala e escrita mostram que elas constituem duas modalidades distintas, mas as diferenças existentes não são exclusivas nem categóricas e, sim, graduais e contínuas, pois, conforme aponta Marcuschi (2001), não existem propriedades que sejam encontradas unicamente em uma dessas modalidades e que estejam presentes em todos os gêneros nela produzidos. Assim, não se pode defender uma oposição completa entre fala e escrita.

Em nossa análise, consideramos, portanto, que as especificidades nos empregos da conjunção aunque não se justificam por uma polarização entre o texto falado e o texto escrito. Tais especificidades podem ser explicadas com base nas propriedades dos gêneros textuais abordados nesta pesquisa a partir do intercruzamento dos eixos da concepção discursiva e do meio de produção. Assim, a entrevista oral, gênero selecionado para representar a modalidade falada, inclui-se no espaço destinado à constelação de entrevistas. Uma vez que apresenta concepção oral e meio de produção oral, as entrevistas localizam-se entre as tipologias textuais da fala, mais próximas da conversação espontânea. Os editoriais jornalísticos, por sua vez, são gêneros tipicamente escritos, que se localizam na fronteira entre os textos instrucionais e os textos acadêmicos, por apresentarem uma concepção escrita e um meio de produção gráfico. Some-se a isso o fato de o grau de formalidade exigido pelos editoriais ser maior do que o exigido na produção de outros textos escritos, como mensagens e cartas pessoais, por exemplo.

\section{0 modelo teórico da Gramática Discursivo-Funcional (GDF)}

A Gramática Discursivo-Funcional (GDF), modelo teórico funcionalista proposto por Hengeveld e Mackenzie (2008), apresenta-se como uma vertente da Gramática Funcional de Dik (1997a, 1997b), por seguir também um modelo estruturado em níveis e camadas organizados hierarquicamente. O diferencial do modelo é a estrutura top-down, uma vez que as decisões tomadas nos níveis hierarquicamente superiores determinam e restringem o funcionamento dos níveis inferiores.

A GDF apresenta quatro níveis de análise: Nível Interpessoal (responsável pelas relações pragmáticas), Nível Representacional (responsável pelas relações semânticas), Nível Morfossintático e Nível Fonológico. A relação entre os níveis procura mostrar que os fenômenos linguísticos que são codificados morfossintática e fonologicamente são motivados por aspectos pragmáticos e/ou semânticos, ou codificados arbitrariamente segundo as propriedades estruturais de cada língua. Outro fator importante é que os níveis, embora independentes, estão em constante interação, sendo que os níveis superiores regem o funcionamento dos níveis inferiores.

A arquitetura descendente do modelo da GDF atende a uma busca de adequação psicológica defendida pelo funcionalismo, ou seja, um modelo teórico de análise deve estar o mais próximo possível do processamento da fala. Assim, com base no 
processamento linguístico da fala descrito por Levelt (1989), o modelo defende que o propósito comunicativo definido inicialmente pelo falante será codificado posteriormente por meio de expressões linguísticas.

A unidade básica de análise da GDF é o Ato Discursivo, que pode ser definido, conforme Kroon (1997, p. 20, tradução nossa6), como "a menor unidade identificável do comportamento comunicativo.". A GDF representa o Componente Gramatical de um processo mais amplo de interação verbal, composto também pelo Componente Conceitual, pelo Componente Contextual e pelo Componente de Saída (Output), conforme pode ser visualizado na figura 1:

Figura 1. A interação entre os componentes na GDF

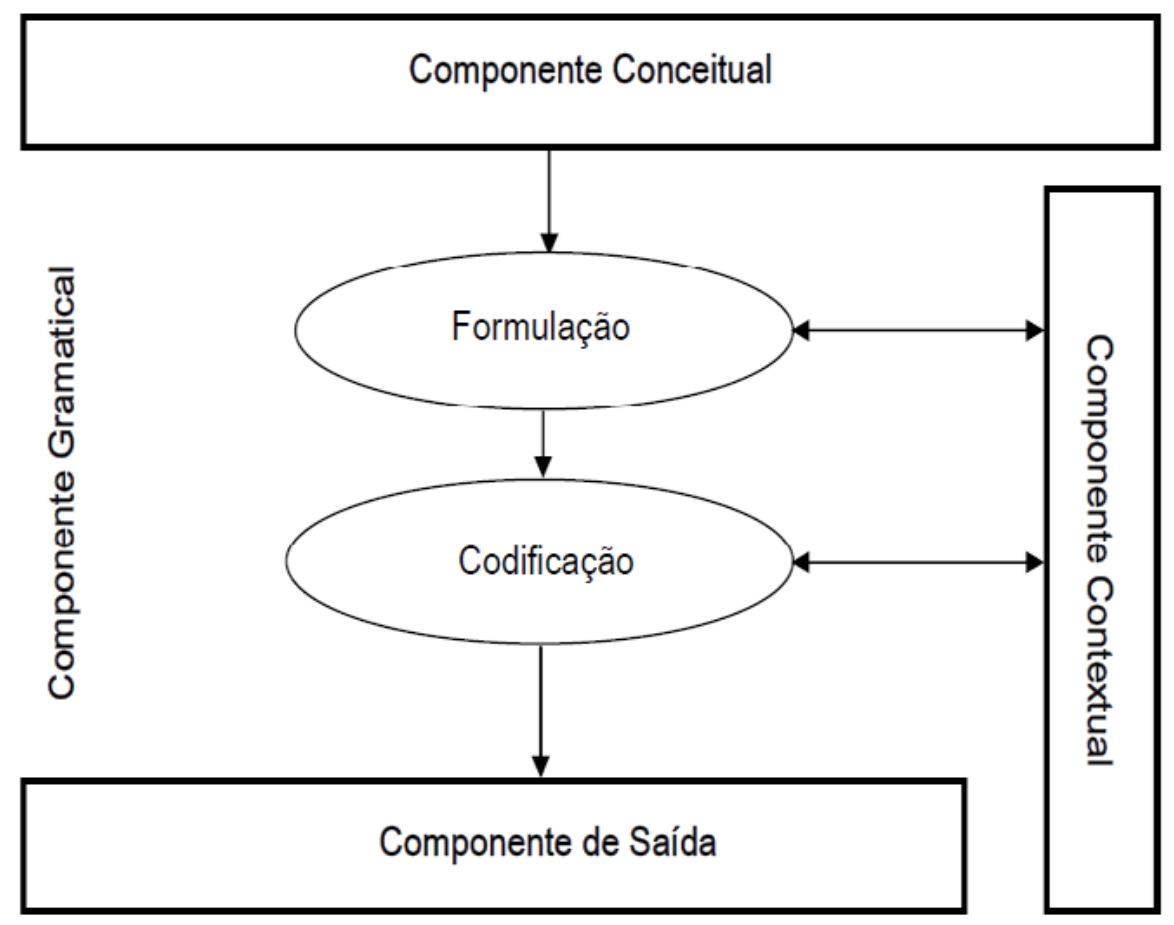

Fonte: Adaptada de Hengeveld e Mackenzie (2008)

Os níveis de análise da GDF estão integrados por uma série de camadas organizadas de maneira hierárquica. As orações concessivas introduzidas pela conjunção aunque, tema de nossa investigação, podem atuar tanto no Nível Interpessoal como no Nível Representacional, razão pela qual apresentamos brevemente, na sequência, as unidades que compõem esses dois níveis.

6 No original: "[...] the smallest identifiable units of communicative behavior". 
O Nível Interpessoal, no qual se representam as relações pragmáticas, "[...] é o nível que lida com todos os aspectos formais de uma unidade linguística que refletem seu papel na interação entre Falante e Ouvinte." (HENGEVELD; MACKENZIE, 2008, p. 46, tradução nossa ${ }^{7}$ ). As unidades do Nível Interpessoal são o Movimento (M), o Ato Discursivo (A), a llocução (F) e o Conteúdo Comunicado (C), que pode conter dois tipos de Subatos, os Subatos de Atribuição ( $T$ ) e os Subatos de Referência (R).

O Nível Representacional, no qual se representam as relações semânticas, tem o papel de atribuir conteúdo semântico às representações que chegam do nível mais alto, o Interpessoal. As unidades mais relevantes do Nível Representacional são o Conteúdo Proposicional (p), o Episódio (ep) e o Estado de Coisas (e).

Como já explicado, as decisões tomadas no Nível Interpessoal e no Nível Representacional, hierarquicamente superiores, resultarão em uma dada codificação das orações concessivas introduzidas por aunque tanto no Nível Morfossintático como no Nível Fonológico.

\section{As unidades introduzidas pela conjunção concessiva aunque no espanhol}

Parra (2016) investigou as orações concessivas introduzidas por aunque no espanhol peninsular falado e escrito e identificou que a conjunção pode introduzir unidades do Nível Representacional e do Nível Interpessoal. Os resultados da investigação realizada pela autora no espanhol confirmaram o que outros autores (GARCIA, 2010; STASSISÉ, 2012; GARCIA; PEZATTI, 2013) já haviam identificado no estudo da concessão em português sob o arcabouço teórico da GDF, a saber, a existência de orações concessivas atuando na camada do Conteúdo Proposicional (Nível Representacional) e na camada do Movimento e do Ato Discursivo (Nível Interpessoal). O estudo de Parra (2016) revelou, ainda, um tipo de oração concessiva introduzida por aunque que modifica a camada da llocução, também do Nível Interpessoal.

No Nível Representacional, a relação presente nas construções concessivas se estabelece entre dois Conteúdos Proposicionais, como já dito. A oração principal traz uma conclusão oposta ao que seria esperado a partir do conhecimento ou crença que se expressa na oração subordinada. Conforme apontam Garcia e Pezatti (2013, p. 483), que investigaram orações concessivas em português, as concessivas da camada do Conteúdo Proposicional atuam como uma espécie de "[...] modificador do núcleo representado pela oração principal [...]".

7 No original: "[...] this is the level that deals with all the formal aspects of a linguistic unit that reflect its role in the interaction between the Speaker and the Addressee".

8 Neste trabalho, não trataremos de aspectos referentes ao Nível Fonológico. 
No Nível Interpessoal, as ocorrências mais frequentes são aquelas em que aunque introduz Atos Discursivos. As concessivas dessa camada dizem respeito à interação entre os participantes de um ato comunicativo e, conforme previsto pela GDF, desempenham uma função retórica. Tais orações trazem uma espécie de ressalva ao todo ou a algum elemento específico enunciado na oração principal, de modo a evitar interpretações equivocadas ou mesmo objeções por parte do ouvinte.

Outra unidade introduzida por aunque no Nível Interpessoal é o Movimento, definido por Hengeveld e Mackenzie (2008) como a maior unidade interacional que é relevante para a análise gramatical, ou seja, as orações introduzidas por aunque que pertencem a essa camada devem corresponder a uma unidade comunicativa completa. Conforme observa Kroon (1997), um Movimento deve apresentar uma unidade comunicativa e uma unidade temática. Para explicar a atuação das orações concessivas que atuam como um Movimento, Parra (2016) recorre, com base em Jubran (2006), ao conceito de tópico discursivo. Num processo real de comunicação, podem existir vários tópicos discursivos, os quais podem estar relacionados por continuidade ou por descontinuidade. No caso específico das orações introduzidas por aunque, a descontinuidade é o processo mais comum, dado que essas orações sempre interrompem um Movimento anterior.

Ainda dentro do Nível Interpessoal, Parra (2016) identificou as concessivas que modificam a camada da llocução, as quais se voltam para o modo como a oração principal é enunciada, isto é, para sua força ilocucionária. Neste caso específico, a concessiva atua como um modificador da llocução da oração principal e indica ao ouvinte o modo como uma determinada Ilocução deve ser interpretada.

\section{Análise das ocorrências nas modalidades falada e escrita}

Para a realização da análise, foram levantadas e analisadas 343 ocorrências de aunque introduzindo orações concessivas finitas, sendo 205 ocorrências provenientes dos editoriais jornalísticos e 138 ocorrências das entrevistas semidirigidas. Os números obtidos mostram que as orações concessivas introduzidas por aunque são mais frequentes nos editoriais jornalísticos do que nas entrevistas semidirigidas. A diferença identificada no emprego da concessão na modalidade falada e na modalidade escrita justifica-se pelas propriedades dos gêneros analisados, como o grau de formalidade exigido em cada um deles e o modo como são concebidos e veiculados.

As entrevistas orais, de concepção e veiculação oral, estão entre os gêneros mais informais no paradigma da modalidade falada proposto por Marcuschi (2001). Nesse tipo de gênero, tanto o falante como o ouvinte são dotados de uma carga comunicativa que deve ser produzida e processada ao mesmo tempo. Desse modo, como aponta Barth (2000), para facilitar a produção e o processamento dos enunciados linguísticos, os interlocutores precisam utilizar mecanismos cognitivos mais simples, por exemplo, a 
coordenação, em detrimento de mecanismos mais complexos, como a subordinação e a própria subordinação concessiva.

Já os editoriais jornalísticos, de concepção gráfica e veiculação escrita, são textos altamente formais, marcados pelo emprego de uma linguagem mais culta e de enunciados mais complexos, como as orações subordinadas, em especial as subordinadas concessivas. O intervalo existente entre a formulação mental do que se pretende enunciar e a efetiva produção escrita é um fator que colabora para produções mais elaboradas nos editoriais.

Retomando nossos critérios de análise (a camada de atuação da oração concessiva a partir da estrutura proposta pela GDF e a informatividade do conteúdo transmitido por essas orações), iniciamos a análise com a apresentação de dados relativos ao primeiro critério. Na tabela 1, observamos o número de ocorrências de cada um dos tipos concessivos identificados nas modalidades investigadas:

Tabela 1. As orações concessivas introduzidas por aunque em relação à camada de atuação

\begin{tabular}{c|c|c|c}
\hline Camada de atuação & Modalidade falada & Modalidade escrita & Resultado geral \\
\hline Conteúdo Proposicional & $74(53,6 \%)$ & $101(49,3 \%)$ & $175(51 \%)$ \\
\hline Ato Discursivo & $35(25,4 \%)$ & $89(43,4 \%)$ & $124(36,2 \%)$ \\
\hline Movimento & $15(10,9 \%)$ & $15(7,3 \%)$ & $30(8,7 \%)$ \\
\hline Modificador interpessoal & $14(10,1 \%)$ & - & $14(4,1 \%)$ \\
\hline TOTAL & 138 & 205 & 343 \\
\hline
\end{tabular}

Fonte: Elaboração própria

Como verificamos na tabela, as orações concessivas de Conteúdo Proposicional são o tipo oracional mais frequente em ambas as modalidades, resultado já esperado, uma vez que tais orações correspondem aos casos típicos de subordinação concessiva, de acordo com as definições de concessão apresentadas pelas gramáticas tradicionais. Embora haja divergências com relação ao número absoluto de ocorrências (mais numerosas na modalidade escrita do que na falada), as porcentagens mostram que há pouca divergência com relação à frequência em ambas as modalidades. Vejamos os exemplos: 
(1) bueno / pues es un pueblo que está en las Alpujarras es donde nace el río Andarax pues la casa es una casa que tiene un huerto que tiene allí unos árboles // eeh y bueno lo pasas bien porque como está alto / aunque / es provincia de Almería / pues / hace fresquito en verano y nada es un pueblo de trescientos habitantes o cosa así (PRESEEA_VALENCIA_ H22_030) ${ }^{9}$

(é um povoado que está nas Alpujarras é onde nasce o rio Andarax, a casa tem um pomar que tem umas árvores, e você se diverte porque como está alto, mesmo sendo na província de Almería, é fresco no verão e é um povoado de trezentos habitantes ou algo assim $)^{10}$

(2) El Gobierno se aferra a la débil explicación de que el paro, aunque sigue creciendo, lo hace con menor intensidad, y encuentra así razones para defender que la reforma laboral acabará por dar resultado. (ED124-05/03/2013)11

(O Governo se agarra à frágil explicação de que o desemprego, embora continue crescendo, faz com menor intensidade, e encontra assim razões para defender que a reforma trabalhista acabará dando resultados)

Em 1, o informante, ao afirmar que o povoado pertence à província de Almeria, cria no ouvinte a expectativa de que o clima do lugar seja quente, dado o que se conhece sobre a região. Tal expectativa, porém, é quebrada pelo enunciado da oração posterior, em que se afirma que o local referido é fresco no verão. A mesma relação de quebra de expectativa é atestada em 2, pois, nessa ocorrência, a premissa inicial de que o desemprego continua crescendo traz uma avaliação negativa do cenário trabalhista, que é, por sua vez, contrariada pela afırmação contida na oração principal de que esse crescimento é menor na atualidade.

O segundo tipo mais frequente nos dados compreende as concessivas de Ato Discursivo, unidades do Nível Interpessoal, que são bem mais numerosas na modalidade escrita do que na modalidade falada. Acreditamos que a maior frequência desse tipo de concessiva na modalidade escrita deve-se ao fato de que os editoriais apresentam maior teor argumentativo, permitindo ao autor desenvolver os tópicos com mais profundidade, o que nem sempre acontece na modalidade falada, em que há muitas interrupções na conversa e no processamento da informação por parte do falante. Vejamos as ocorrências:

9 As informações que acompanham as ocorrências da modalidade falada fazem referência ao nome do projeto, seguido da cidade espanhola, do sexo do informante (H para homem e M para mulher), do código do informante e do número que a entrevista recebe dentro do projeto.

10 As traduções que propomos para o português representam uma tentativa de auxiliar o leitor não proficiente em espanhol na interpretação das ocorrências.

11 As informações que acompanham as ocorrências da modalidade escrita fazem referência ao gênero editorial (ED), seguido do número que identifica o editorial no conjunto de textos coletados e da data de publicação do editorial no site do jornal. 
(3) por ejemplo yo la compra/ ee de alimentación y eso/ la hago en Granada y la la en general la compra de ropa y eso Eulalia también la hace en Granada/ aunque algunos hay/l algunos sitios aquí en los que en fin empieza// a/ a haber algo más ¿no? (PRESEEA_ GRANADA_H32_07)

(por exemplo, a compra de alimentos eu faço em Granada e em geral a compra de roupas Eulália também faz em Granada, embora haja alguns lugares aqui que enfim começam a ter algo a mais, né?)

(4) La desaparición de Chávez deja también un significativo vacío, cuando no infunde un abierto temor, más allá de las fronteras de su país. El caudillo populista trabajó incansablemente para convertir a Venezuela en un actor internacional, aunque en ocasiones fuese a costa de formalizar alianzas con cualquier Gobierno despótico que se opusiera abiertamente a EE UU: la Libia de Gadafi, Corea del Norte, Irán o Siria. (ED12907/03/2013)

(O desaparecimento de Chávez deixa também um vazio significativo, quando não traz um temor aberto, para além das fronteiras de seu país. O líder populista trabalhou incansavelmente para converter a Venezuela em um ator internacional, embora em certas ocasiões fosse a custo de fazer alianças com qualquer governo despótico que se opusesse abertamente aos EUA: a Líbia de Gadafi, a Coreia do Norte, o Irã ou a Síria.)

A relação concessiva entre Atos Discursivos corresponde a uma função retórica na qual o Ato Subsidiário faz uma ressalva ao Ato Nuclear, enunciado anteriormente. Assim, em 3, vemos que o falante, após dizer que ele e sua família fazem todas as compras em Granada, sente a necessidade de esclarecer que o comércio de sua cidade está começando a se desenvolver. Com o comentário enunciado na oração concessiva, que constitui o Ato Discursivo Subsidiário, o falante visa a evitar uma avaliação negativa de sua cidade por parte do ouvinte, possivelmente causada pela afırmação contida no Ato Nuclear. Em 4, o Ato Discursivo iniciado por aunque busca atenuar a afırmação anterior de que o então presidente da Venezuela, Hugo Chávez, fez o possível para colocar seu país no cenário mundial, ao esclarecer que algumas vezes as alianças foram feitas com os líderes mundialmente conhecidos pelo caráter ditatorial de seus governos.

No caso das orações concessivas da camada do Movimento, os dados apresentam uma mesma quantidade de ocorrências em ambas as modalidades, demonstrando, assim, que o uso da conjunção aunque enquanto marcador discursivo, voltado para introduzir inserções e parênteses ou iniciar um novo tópico comunicativo, é uma estratégia argumentativa produtiva nas modalidades falada e escrita do espanhol peninsular, que precisa ser considerada nos estudos relacionados à concessão nessa língua. Vejamos as ocorrências: 
(5) el fin de semana que viene// lo tengo libre// bueno tengo guardia el viernes/ salgo el sábado a las nueve y media// o a las diez// y tengo/ sábado y domingo lo tengo libre/// porque ya el/ siguiente// tengo/ el sábado me toca guardia en el centro de salud/// al siguiente tengo un viaje/ aunque ese es más de hobby que de otra cosa/ pero en fin/ también// también gusta/ y al siguiente tengo un curso/ (PRESEEA_GRANADA_M32_10)

(tenho o final de semana que vem livre, bom, tenho plantão na sexta, saio no sábado às nove e meia ou às dez e tenho o sábado e o domingo livres, porque já no seguinte tenho plantão no sábado no centro de saúde, no seguinte tenho uma viagem, embora essa seja mais de hobby do que de outra coisa - mas, enfim, também no fim de semana seguinte tenho um curso)

(6) La líder democristiana afrontaría así su tercer mandato, siempre en alianza, ora con los socialdemócratas, ora con los liberales. La convocatoria es importante para Europa; no en vano afecta al país más poblado, líder de su economía y de su política económica, y el que da forma, en gran medida, a todo el discurso político comunitario, que no puede enhebrarse sin su concurso directo o aquiescencia. Aunque ese justificado interés que los comicios despiertan en el resto de Europa no implica que vayan a transformar radicalmente el escenario de la política continental, bastante encarrilada en un lustro de crisis. (ED52820/09/2013)

(A líder democrata-cristã afrontaria assim seu terceiro mandato, sempre em aliança, ora com os social-democratas, ora com os liberais. A convocatória é importante para a Europa; não em vão afeta o país mais povoado, líder de sua economia e de sua política econômica, e o que dá forma, em grande medida, a todo o discurso político comunitário, que não pode se alinhar sem sua participação direta ou seu consentimento. Embora esse interesse justificado que os comícios despertam no resto da Europa não implique que vão transformar radicalmente o cenário da política continental, bastante envolvida em um período de crises)

Em 5, o Movimento introduzido por aunque interrompe momentaneamente o Movimento em andamento, no qual se discutiam os compromissos da informante para os próximos finais de semana. Assim, o Movimento concessivo atua como uma digressão, na qual se insere um comentário que o falante julga relevante para a compreensão do discurso. Nesse caso, o objetivo da informante era esclarecer que sua viagem não era a trabalho. Terminada a inserção parentética feita pelo Movimento concessivo, o tópico tratado no Movimento interrompido é retomado pelo uso do marcador pero.

Já em 6, embora aunque também atue na camada do Movimento, a estratégia utilizada não é mais a de inserir um parêntese no discurso em andamento, mas sim a de introduzir um novo tópico discursivo que se volta para o tópico desenvolvido no Movimento anterior. Nessa ocorrência, o Movimento inicial discorre sobre como as eleições na Alemanha são relevantes para o cenário europeu, dada a importância desse país no plano econômico. O Movimento introduzido por aunque, por sua vez, aborda a baixa probabilidade de 
mudanças na política do continente caso a ministra Angela Merkel vença as eleições. Esse posicionamento contrasta com o assunto que vinha sendo tratado no Movimento anterior.

As orações concessivas que atuam na camada da llocução correspondem a um tipo oracional característico da modalidade falada. Tal uso representa uma estratégia favorecida pelo gênero entrevista semidirigida, que propicia o aparecimento desse tipo oracional por constituir um diálogo baseado em perguntas e respostas, o que gera mudanças de llocução e o uso de recursos linguísticos para preservar a face dos participantes e motivar o andamento da interação entre pessoas geralmente desconhecidas. Vejamos algumas ocorrências:

A: muy bien/ yy/ ¿tus años en la escuela? aunque fueras cambiando de pueblo/ ¿alguna escuela? ¿algún maestro en especial?/ (PRESEEA_VALENCIA_H231_02)

(A: muito bem, e seus anos na escola? embora você fosse mudando de cidade, alguma escola? algum professor em especial?)

(8) E: tú / aunque ahora no estéis casados ni tenéis hijos / pero / tú sabes que la relación tuya con tus padres / la forma de educarte de tus padres a ti [...] ¿y tú educarás a tus hijos igual o hay cambios? (PRESEEA_VALENCIA_H11_065)

(E: embora agora vocês não estejam casados nem tenham filhos, mas você sabe que sua relação com seus pais, a forma de educar dos seus pais [...] e você educará os seus filhos igual ou há mudanças?)

Nessas ocorrências, as orações introduzidas por aunque carregam uma informação compartilhada pelos interlocutores que deveria impedir, mas não impede, a enunciação do Ato Discursivo que as segue. Assim, em 7, o entrevistador, mesmo sabendo que o informante passou sua infância mudando de cidade por causa do emprego de seu pai e, em razão disso, possa não ter criado vínculos nas escolas onde estudou, pergunta se alguma escola ou se algum professor foi especial para ele. O mesmo tipo de relação é vista em 8, pois o fato de o entrevistador saber que o entrevistado não é casado nem tem filhos deveria inibir perguntas sobre como criar os filhos; no entanto, o entrevistador, embora reconheça esse obstáculo, questiona se o entrevistado pretende educar seus filhos do mesmo modo como foi educado.

Podemos notar que, em ambas as ocorrências, a oração concessiva e a oração com a qual ela se relaciona apresentam Ilocuções diferentes: declarativa na primeira e interrogativa na segunda. E a oração introduzida por aunque acaba por atuar como uma espécie de modificador da oração principal. 
Tendo em vista a diversidade de tipos concessivos que a conjunção aunque é capaz de introduzir, consideramos que o uso frequente dessa conjunção frente às demais estratégias para marcar a concessão no espanhol peninsular deve-se ao fato de aunque estabelecer tanto relações interpessoais como semânticas, marcando uma atuação nos níveis Interpessoal e Representacional.

Nosso segundo critério de análise, a informatividade, pode ser definido, de acordo com Pérez Quintero (2002), como as estratégias que um falante assume para codificar sua mensagem, com base no que ele imagina compor o conhecimento de seu interlocutor. Assim, o contexto textual e o contexto situacional, bem como o conhecimento de mundo e as crenças dos participantes da interação são aspectos que definem o caráter pressuposto ou não-pressuposto da oração concessiva.

Desse modo, a partir da proposta de Pérez Quintero (2002), consideramos pressuposta a informação que o falante apresenta como dada, isto é, como já conhecida pelo ouvinte, seja por já ter sido anteriormente enunciada na interação, por fazer parte do contexto situacional, ou ainda porque o falante pressupõe que tal informação já faça parte do conhecimento de mundo do seu interlocutor.

A informação não-pressuposta, por sua vez, é aquela que o falante apresenta como nova para o interlocutor, seja por não ter sido enunciada no contexto precedente, por não ser recuperável dentro do contexto situacional ou porque o falante imagina que tal informação não integre o conhecimento de mundo de seu interlocutor. Vejamos os exemplos:

(9) Un registro de morosos es una idea arriesgada, fácil de enunciar pero difícil de aplicar con precisión. Puede tener complicaciones con la Ley de Protección de Datos si no establece las debidas cautelas para la difusión de la información.[...] Aunque sobre el papel se suelen dar garantías de confidencialidad (que la información solo se use y se difunda para el fin que se elaboró la lista negra), en la realidad cualquier registro se usa con los fines más dispares e inadecuados. (ED76-08/02/2013)

(Um registro de inadimplentes é uma ideia arriscada, fácil de falar, mas difícil de aplicar com precisão. Pode ter complicações com a Lei de Proteção de Dados se não estabelece os devidos cuidados para a difusão da informação. [...] Embora sobre o papel se costumem dar garantias de confidencialidade (que a informação só se utilizará e se difundirá para o fim com que se elaborou a lista negra), na realidade qualquer registro se utiliza com os fins mais díspares e inadequados.) 
(10) A: ¿tú volvías con bastante frecuencia de Ciudad Real aa tu casa o no?

B: cada quince días posiblemente/ sí/ aunque bueno/ del cuartel salía/ prácticamente todos los fines de semana// porquee hice muy buenos amigos yy-y insistían en que fuese a su casa (PRESEEA_VALENCIA_H431_04)

(A: você voltava com bastante frequência de Cidade Real para a sua casa ou não?

B: a cada quinze dias possivelmente, sim, embora saísse do quartel praticamente todos os fins de semana, porque fiz muitos bons amigos e insistiam para que eu fosse à casa deles)

A ocorrência 9 está inserida em um editorial que trata da criação de um registro nacional de inquilinos devedores, com o objetivo de facilitar a vida dos proprietários que querem alugar seus imóveis sem ter problemas com inquilinos inadimplentes. Vemos que a informação contida na oração concessiva em destaque retoma, portanto, um saber comum - que na prática é contrariado - de que os acordos feitos no papel buscam sempre estar em conformidade com as leis. Por fazer parte do conhecimento de mundo dos interlocutores, a informação introduzida por aunque em 9 é classificada como pressuposta.

Em 10, vemos que a oração concessiva traz uma informação até então desconhecida do entrevistador por ser ela mesma uma resposta à pergunta feita por ele. Logo, o conteúdo introduzido por aunque nessa ocorrência é avaliado como não-pressuposto.

Apresentamos, na sequência, os resultados referentes à informatividade em relação às camadas de atuação das orações introduzidas por aunque que descrevemos anteriormente.

Tabela 2. A informatividade das orações concessivas introduzidas por aunque em relação à camada de atuação

\begin{tabular}{c|c|c|c|c|c|c}
\hline & \multicolumn{2}{|c|}{ Modalidade falada } & \multicolumn{2}{c|}{ Modalidade escrita } & \multicolumn{2}{c}{ Resultado geral } \\
\hline Camada de atuação $^{12}$ & pres & não pres & pres & não pres & pres & não pres \\
\hline Concessivas de p & $\begin{array}{c}32 \\
(47,8 \%)\end{array}$ & $\begin{array}{c}42 \\
(59,2 \%)\end{array}$ & $\begin{array}{c}70 \\
(46,4 \%)\end{array}$ & $\begin{array}{c}31 \\
(57,4 \%)\end{array}$ & $\begin{array}{c}102 \\
(46,8 \%)\end{array}$ & $\begin{array}{c}73 \\
(58,4 \%)\end{array}$ \\
\hline Concessivas de A & 17 & 18 & 71 & 18 & 88 & 36 \\
$(25,4 \%)$ & $(25,3 \%)$ & $(47 \%)$ & $(33,3 \%)$ & $(40,4 \%)$ & $(28,8 \%)$ \\
\hline Concessivas de M & 4 & 11 & 10 & 5 & 14 & 16 \\
$(6 \%)$ & $(15,5 \%)$ & $(6,6 \%)$ & $(9,3 \%)$ & $(6,4 \%)$ & $(12,8 \%)$ \\
\hline
\end{tabular}

12 As variáveis presentes na tabela correspondem às unidades da teoria da GDF já apresentadas, ou seja, o Conteúdo Proposicional (p), o Ato Discursivo (A), o Movimento (M) e a llocução (F). 


\begin{tabular}{c|c|c|c|c|c|c}
\hline Concessivas de F & $\begin{array}{c}14 \\
(20,9 \%)\end{array}$ & --- & --- & --- & $\begin{array}{c}14 \\
(6,4 \%)\end{array}$ & --- \\
\hline TOTAL & $\begin{array}{c}67 \\
(100 \%)\end{array}$ & $\begin{array}{c}71 \\
(100 \%)\end{array}$ & $\begin{array}{c}151 \\
(100 \%)\end{array}$ & $\begin{array}{c}54 \\
(100 \%)\end{array}$ & $\begin{array}{c}218 \\
(100 \%)\end{array}$ & $\begin{array}{c}125 \\
(100 \%)\end{array}$ \\
\hline
\end{tabular}

Fonte: Elaboração própria

Verificamos, com base nos resultados apresentados na tabela 2, que existe uma diferença entre as ocorrências da modalidade falada e as ocorrências da modalidade escrita no que refere à informatividade das orações concessivas introduzidas por aunque. Na primeira, predominam os casos de informação não-pressuposta, enquanto na segunda predominam os casos de informação pressuposta.

Nas ocorrências de modalidade falada, a pressuposição é categórica unicamente no caso das concessivas que atuam na camada da llocução, pois esse tipo oracional apresenta a propriedade de sempre transmitir um conteúdo já enunciado no contexto precedente ou já experienciado pelos interlocutores.

As concessivas que atuam na camada do Conteúdo Proposicional, do Ato Discursivo e do Movimento distribuem-se de maneira irregular em ambas as modalidades, pois tendem a apresentar conteúdos não-pressupostos na modalidade falada e conteúdos pressupostos na modalidade escrita. Considerando que as unidades são as mesmas nas duas modalidades, concluímos que a informatividade é uma propriedade motivada pelo gênero textual e não pela camada da oração.

No gênero entrevista, cabe ao entrevistador indicar ao entrevistado, por meio de perguntas, o assunto a ser discutido. Faz parte do nosso conhecimento linguístico que um ato de natureza interrogativa tem como função principal a busca de uma informação que o falante desconhece, mas que imagina fazer parte do conhecimento de mundo do seu interlocutor. Assim, durante a entrevista, o entrevistado tende a responder às perguntas do entrevistador, por entender que o que está enunciando é algo novo para ele, fato que explica a maior frequência de orações concessivas contendo informação não-pressuposta. Como podemos observar na maioria das entrevistas que integram o PRESEEA, entrevistador e entrevistado não se conhecem, o que favorece o fato de que as informações fornecidas pelo entrevistado, entre elas as representadas por orações introduzidas por aunque, trazem, geralmente, conteúdos não-pressupostos.

Por outro lado, o gênero editorial jornalístico, que representa a modalidade escrita, caracteriza-se por tratar de questões políticas, econômicas e sociais que estão presentes no cenário nacional e internacional. Desse modo, os textos que pertencem a esse gênero estão em constante diálogo com outras notícias publicadas na mesma edição do jornal ou em edições anteriores, pressupondo que o leitor tenha conhecimento dos fatos 
relatados. Assim, o mais provável é que as orações concessivas tragam informações compartilhadas pelos interlocutores e, portanto, de conhecimento pressuposto.

\section{Considerações finais}

O presente trabalho teve por objetivo verificar, a partir dos subtipos oracionais introduzidos pela conjunção concessiva aunque no espanhol peninsular, quais são os usos mais prototípicos das modalidades falada e escrita. Partimos da análise realizada por Parra (2016), que, com base no aparato teórico da Gramática Discursivo-Funcional (HENGEVELD; MACKENZIE, 2008), identificou orações concessivas que podem atuar na camada do Conteúdo Proposicional (unidade do Nível Representacional) e também nas camadas no Movimento, do Ato Discursivo e da Ilocução (unidades do Nível Interpessoal).

A partir da análise empreendida pela autora e do córpus por ela organizado, verificamos como as orações concessivas introduzidas por aunque se distribuem entre as modalidades falada e escrita do espanhol, tendo como amostras de fala entrevistas orais semidirigidas, extraídas do Projeto PRESEEA, e como amostras de escrita, editoriais jornalísticos publicados on-line no jornal espanhol El País.

Os dados mostram que as orações concessivas introduzidas por aunque são mais frequentes nos editoriais do que nas entrevistas, o que nos confirma que a concessão é um fenômeno típico da escrita, em especial da escrita de natureza mais formal, como já havia sido apontado por outros autores, como Algeo (1973), Barth (2000) e também Neves (2002).

Como critérios de análise, observamos a camada de atuação da oração concessiva introduzida por aunque e a informatividade do conteúdo transmitido por essas orações, de modo a verificar se a informação era pressuposta ou não-pressuposta.

Com relação à camada de atuação, a análise mostra que as concessivas da camada do Conteúdo Proposicional, do Movimento e do Ato Discursivo podem ocorrer tanto na modalidade falada como na modalidade escrita. As orações concessivas que atuam na camada da llocução, dada sua natureza interativa, são exclusivas da modalidade falada.

As orações que atuam na camada do Conteúdo Proposicional do Nível Representacional e que representam o tipo concessivo mais comumente tratado nas gramáticas, por ser o mais prototípico, ocorrem com elevada frequência em ambas as modalidades.

As ocorrências de orações concessivas na camada do Ato Discursivo e do Movimento, unidades do Nível Interpessoal, são frequentes tanto na modalidade falada como na modalidade escrita e comprovam que a concessão também pode representar uma 
estratégia de interação entre os participantes do processo comunicativo e não só estabelecer uma relação semântica de quebra de expectativa, como ocorre com as concessivas do Nível Representacional. Consideramos que o alto número de orações concessivas atuando como Ato Discursivo na modalidade escrita pode ser justificado pelo elevado teor argumentativo dos contextos em que essas orações são empregadas, o que requer do falante a produção de esclarecimentos e ressalvas, estratégias características dos Atos Discursivos concessivos.

Com relação à informatividade, a análise revela que a pressuposição ou nãopressuposição do conteúdo das orações concessivas de Conteúdo Proposicional, de Ato Discursivo e de Movimento é uma propriedade condicionada pelo gênero textual. As entrevistas orais, por corresponderem a um tipo de interação baseado em perguntas e respostas entre pessoas que na maioria das vezes não se conhecem, favorecem o emprego de concessivas de conteúdo não-pressuposto. Os editoriais jornalísticos, por outro lado, favorecem o emprego de concessivas de conteúdo pressuposto, uma vez que estabelecem diálogos com notícias já veiculadas e conhecidas do leitor.

\section{Agradecimentos}

As autoras agradecem o apoio financeiro da Coordenação de Aperfeiçoamento de Pessoal do Nível Superior no Brasil (CAPES) - Código de Financiamento 001, por meio do Programa de Pós-graduação em Estudos Linguísticos do IBILCE/UNESP (PPGEL/ CAPES/PROEX).

\section{REFERÊNCIAS}

ALARCOS LLORACH, E. Gramática de la Lengua Española. Madrid: Espasa, 1999.

ALGEO, J. E. The concessive conjunction in Medieval Spanish and Portuguese; its function and development. Romance philology, Turnhout, n. 26, p. 532-545, 1973.

BARTH, D. "That's true, although not really, but still": expressing concession in spoken English. In: COUPER-KUHLEN, E.; KORTMANN, B. (ed.). Cause, condition, concession, contrast cognitive and discourse perspectives. Berlin: Mouton de Gruyter, 2000. p. 411- 437.

CHAVES, C. C. Conectivos como estratégia argumentativa: uma análise dos editoriais de Veja. Revista Philologus, v. 20, p. 293-308, 2014. Disponível em: http://www.filologia.org. br/vi_sinefil/resumos/conectivos_como_estrategia_CHARLESTON.pdf. Acesso em: 29 jul. 2014. 
CREVELS, M. Concession in Spanish. In: HANNAY, M.; BOLKESTEIN, A. M. Functional Grammar and verbal interaction. Amsterdam: John Benjamins, 1998. p. 129-148.

DIK, S. C. The theory of Functional Grammar. Part 1: The Structure of the Clause. Edited by Kees Hengeveld. 2. ed. Berlin: Mouton de Gruyter, 1997a.

DIK, S. C. The theory of Functional Grammar. Part 2: Complex and Derived Constructions. Edited by Kees Hengeveld. Berlin: Mouton de Gruyter, 1997b.

GARCIA, T. S. As relações concessivas no português falado sob a perspectiva da Gramática Discursivo-Funcional. 2010. Tese (Doutorado em Estudos Linguísticos) - Instituto de Biociências, Letras e Ciências Exatas, Universidade Estadual Paulista "Júlio de Mesquita Filho", São José do Rio Preto, 2010.

GARCIA, T. S. G.; PEZATTI, E. G. Orações concessivas independentes à luz da Gramática Discursivo-Funcional. Alfa, São Paulo, v. 57, n. 2, p. 475-494, 2013.

HENGEVELD, K.; MACKENZIE, J. L. Functional Discourse Grammar: a typologically-based theory of language structure. Oxford: Oxford University Press, 2008.

JUBRAN, C. C. A. S. Tópico discursivo. In: JUBRAN, C. C. A. S.; KOCH, I. G. V. Gramática do português culto falado no Brasil. v. 1: construção do texto falado. Campinas: Editora da UNICAMP, 2006. p. 89-132.

KOCH, P.; ÖSTERREICHER, W. Gesprochene Sprache in der Romania: Französisch, Italienisch, Spanisch. Tübingen: Niemeyer, 1990.

KROON, C. Discourse markers, discourse structure and Functional Grammar. In: CONNOLLY, J. et al. (ed.). Discourse and pragmatics in functional grammar. Berlin: Mouton de Gruyter, 1997. p. 17-32.

LEVELT, W. J. M. Speaking: from intention to articulation. Cambridge: The MIT Press, 1989.

MARCUSCHI, L. A. Da fala para a escrita: atividades de retextualização. São Paulo: Cortez, 2001.

NEVES, M. H. M. A gramática: história, teoria e análise, ensino. São Paulo: Editora da UNESP, 2002. 
PARRA, B. G. G. Uma investigação discursivo-funcional das orações concessivas introduzidas por aunque em dados do espanhol peninsular. 2016. Dissertação (Mestrado em Estudos Linguísticos) - Instituto de Biociências, Letras e Ciências Exatas, Universidade Estadual Paulista "Júlio de Mesquita Filho", São José do Rio Preto, 2016.

PÉREZ QUINTERO, M. J. Adverbial Subordination in English: a functionalist approach. Amsterdam: Rodopi, 2002.

REAL ACADEMIA ESPAÑOLA; ASOCIACIÓN DE LAS ACADEMIAS DE LA LENGUA ESPAÑOLA. Nueva gramática de la lengua española. Madrid: Espasa Libros, 2009.

STASSI-SÉ, J. C. Subordinação discursiva no português à luz da gramática discursivofuncional. 2012. Tese (Doutorado em Estudos Linguísticos) - Instituto de Biociências, Letras e Ciências Exatas, Universidade Estadual Paulista "Júlio de Mesquita Filho", São José do Rio Preto, 2012. 